\title{
Beneficial effects of a WC addition in FAST-densified tungsten
}

\author{
Sasa Novak ${ }^{\mathrm{a}, \mathrm{b}, *}$, Matej Kocen ${ }^{\mathrm{a}, \mathrm{b}}$, Andreja Sestan Zavasnik ${ }^{\mathrm{b}, \mathrm{c}}$, Andrei Galatanu ${ }^{\mathrm{d}}$, \\ Magdalena Galatanu ${ }^{\mathrm{d}}$, Sandra Tarancon ${ }^{\mathrm{e}}$, Elena Tejado ${ }^{\mathrm{e}}$, Jose Ygnacio Pastor $^{\mathrm{e}}$, Petra Jenus ${ }^{\mathrm{a}}$ \\ ${ }^{a}$ Dept. for Nanostructured Materials, Jozef Stefan Institute, Ljubljana, Slovenia \\ ${ }^{\mathrm{b}}$ Jozef Stefan International Postgraduate School, Ljubljana, Slovenia \\ ${ }^{\mathrm{c}}$ Center for Electron Microscopy, Jozef Stefan Institute, Ljubljana, Slovenia \\ ${ }^{\mathrm{d}}$ National Institute of Materials Physics, Magurele, Romania \\ ${ }^{\mathrm{e}}$ Dpto. de Ciencia de Materiales-CIME, Universidad Politecnica de Madrid, Spain
}

Keywords:

Tungsten

Tungsten carbide

$\mathrm{W}_{2} \mathrm{C}$

Particle reinforcement

FAST

Fusion power plants

\begin{abstract}
A B S T R A C T
The particle reinforcement of fusion-relevant tungsten through the incorporation of tungsten sub-carbide $\mathrm{W}_{2} \mathrm{C}$ particles at the grain boundaries is demonstrated as an effective way of eliminating the harmful $\mathrm{W}$ oxide, enhancing densification and stabilising the composite's microstructure and flexural strength at room and high temperatures. The $\mathrm{W}_{2} \mathrm{C}$ particles are formed in situ during the sintering by carbon diffusion from WC nanoparticles added as a precursor to the $\mathrm{W}$ matrix. Even in an extremely fast sintering process using Field-Assisted Sintering Technology (FAST, 1900 C, $5 \mathrm{~min}$ ), the added WC completely transforms to $\mathrm{W}_{2} \mathrm{C}$, resulting in a $\mathrm{W}-\mathrm{W}_{2} \mathrm{C}$ composite. While at least $5 \mathrm{vol} \%$ of WC nanoparticles are needed to eliminate the oxide, approximately 10 vol \% result in a $\mathrm{W}-\mathrm{W}_{2} \mathrm{C}$ composite with favourable characteristics: high density, high flexural strength at RT ( $>1200 \mathrm{MPa})$ as well as at elevated temperatures, and high thermal conductivity, which remains above $100 \mathrm{~W} /$ mK up to $1000 \mathrm{C}$.
\end{abstract}

\section{Introduction}

The development and implementation of fusion power plants promise a significant contribution to clean and safe energy supply for future generations. To ensure their high efficiency and safe operation, extensive efforts are being put into the development of suitable structural materials, capable of withstanding the extreme conditions in the reactor. Within the design of the demonstration power plant (DEMO), one of the essential tasks is to select suitable material for the divertor, which is a critical in-vessel component. The divertor is responsible for heat transfer and impurity removal via a guided plasma exhaust and is, therefore, subjected to very high heat fluxes. Although recent decades have seen substantial progress in the field of fusion-relevant materials, the development of improved materials remains among the priorities of fusion research programmes. The goal is to prepare a low-activation material capable of withstanding high heat loads of more than $10 \mathrm{MW} / \mathrm{m}^{2}$, with sufficient mechanical and thermal properties, which are retained even after high neutron irradiation dose and nuclear transmutations [1-3].

Current research focuses on the development of tungsten-based materials. They demonstrate some attractive thermo-physical properties; however, these properties deteriorate under operating conditions. For example, the ductile-to-brittle transition (DBT) in the temperature range around $400 \mathrm{C}$ as well as the recovery, recrystallization and excessive grain growth at temperatures above $1000 \mathrm{C}$, are obstacles for the use of pure tungsten in the proposed operational window of the DEMO reactor $[1,4,5]$.

The currently proposed solutions for the structural stabilisation of tungsten include particle reinforcement by the incorporation of oxide (e. g. $\mathrm{Y}_{2} \mathrm{O}_{3}$ ) or carbide (e.g. TiC, $\mathrm{TaC}$ ) particles into the $\mathrm{W}$ matrix that was demonstrated to improve the material's mechanical properties to a certain extent [6-10]. As an alternative, we recently proposed the reinforcement of tungsten with $\mathrm{W}_{2} \mathrm{C}$ particles synthesised through the reaction of a carbide precursor during sintering [11].

A variety of precursors were verified: graphene, phenolformaldehyde resin and WC nanoparticles. It was confirmed that during pressureless sintering at $2200 \mathrm{C}$ in a vacuum furnace all three precursors resulted in the formation of $\mathrm{W}_{2} \mathrm{C}$ inclusions, but only in the case of a WC addition were no carbonaceous residues found. Therefore, we selected the WC nanoparticles as the most suitable precursor. As

\footnotetext{
* Corresponding author. Dept. for Nanostructured Materials, Jozef Stefan Institute, Jamova c. 39, 1000, Ljubljana, Slovenia.

E-mail address: sasa.novak@ijs.si (S. Novak).
} 
presented in the paper [11], the $\mathrm{W}_{2} \mathrm{C}$ inclusions enhanced densification and inhibited the $\mathrm{W}$ grain growth during sintering. Even more importantly, the grain growth was also inhibited during prolonged ageing at high temperatures.

This work aimed to verify the formation of $\mathrm{W}_{2} \mathrm{C}$ particles at the $\mathrm{W}$ grain boundaries during sintering by Field-Assisted Sintering Technology (FAST), an advanced consolidation technique, able to efficiently densify materials in a very short time and at a lower temperature than with conventional sintering. The WC nanoparticles were used as a precursor for the $\mathrm{W}_{2} \mathrm{C}$ inclusions. Special attention was paid to the phase composition after the FAST sintering, in particular to the presence of $\mathrm{W}_{2} \mathrm{C}$ and oxides. The effect of inclusions on the mechanical properties and the thermal conductivity was analysed from room temperature to $1200 \mathrm{C}$. The effect of ageing during $24 \mathrm{~h}$ of heating at $1600 \mathrm{C}$ on the microstructure and the mechanical properties was also verified.

\section{Experimental}

\subsection{Sample preparation}

Tungsten powder with an average grain size of $1.5 \mu \mathrm{m}$ (Global Tungsten \& Powders spol. S r.o., Czech Republic) was used in this study. According to the producer's specification, the oxygen content in the powder was $0.105 \mathrm{wt} \%$, i.e., 1.2 at. \%. The tungsten powder was mixed with WC powder (150-200 nm, >99\%, Aldrich, Germany) in cyclohexane (Sigma Aldrich, Germany) and homogenised with an ultrasonic processor VCX500 (Sonics \& Materials Inc., USA) for $3 \mathrm{~min}$ at a power of $250 \mathrm{~W}$, frequency $20 \mathrm{kHz}$ and pulse on/off of $1 \mathrm{~s}$. The powder mixtures with compositions presented in Table 1 were sintered in a graphite die with an inner diameter of $16 \mathrm{~mm}$ using field-assisted sintering (FAST, Dr. Sinter FAST 515-S, Sumimoto FAST Syntex Ltd., Japan) at $1900 \mathrm{C}$ with a heating rate of $100 \mathrm{C} / \mathrm{min}$, for $5 \mathrm{~min}$ and an applied pressure of $60 \mathrm{MPa}$. Before the FAST processing, the reaction chamber was purged several times with high-purity argon and evacuated again. During sintering, the pressure inside the chamber was below $10 \mathrm{~Pa}$. For comparison, pure tungsten (sample $\mathrm{W}$ ) was sintered in a high-temperature vacuum furnace $(30 \mathrm{~Pa})$ with graphite heating elements (Thermal Technology, USA) at $2200 \mathrm{C}$ for $6 \mathrm{~h}$. Additionally, the sintered samples were aged at $1600 \mathrm{C}$ for $24 \mathrm{~h}$ in a vacuum.

\subsection{Characterisation}

Before the analysis, we removed the outer, carbon-contaminated, layer of the sintered material by grinding. The phase composition of the sintered samples was analysed by X-ray diffraction (XRD; AXS U8, Bruker Co., USA) utilising $\mathrm{Cu}-\mathrm{K} \alpha$ radiation at room temperature (step width of 0.02 , fixed time of $1 \mathrm{~s}$, a scanning range of $2 \theta \quad 20-80$ ). A Rietveld analysis was performed using the programme package Topas, Bruker AXS, Karlsruhe, Germany.

The microstructures of the samples before and after hightemperature ageing were characterised by scanning electron microscopy (FE-SEM, JSM-7600F, Jeol Inc., Japan). For the detection and identification of the secondary phase, electron-backscatter diffraction (EBSD; HKL Channel 5, Oxford Instruments plc, UK) mapping was performed. Before the EBSD analysis, the samples were etched with an OPS

Table 1

Composition of the samples.

\begin{tabular}{|c|c|c|}
\hline Sample & $\begin{array}{l}\text { Composition of the powder } \\
\text { mixtures (vol. \%) }\end{array}$ & $\begin{array}{l}\text { Concentration of carbon in the } \\
\text { starting mixture (at. \%) }\end{array}$ \\
\hline W & W & 0 \\
\hline W-1WC & $99 \mathrm{~W}$ & 0.75 \\
\hline W-5WC & $5 \mathrm{WC}$ & 3.7 \\
\hline W-10WC & $10 \mathrm{WC}$ & 7.2 \\
\hline W-25WC & $25 \mathrm{WC}$ & 16.7 \\
\hline
\end{tabular}

solution ( $5 \mathrm{vol} \% \mathrm{H}_{2} \mathrm{O}_{2}$ solution in colloidal silica) to remove the plastically deformed tungsten layer. The average tungsten grain size was obtained from a planimetric analysis conducted on four SEM micrographs per sample, taking into account 300 grains using imageanalysis software (ImageJ software package (v. 1.50b, 2015, Wayne Rasband, National Institutes of Health, Bethesda, MD, USA).

The mechanical properties of the as-sintered and aged (1600 C for $24 \mathrm{~h}$ ) samples were evaluated at room temperature by a ball-on-threeballs flexural strength test (Galdabini Quasar 50, Italy). Three samples per composition were tested.

The high-temperature flexural strength was measured in a vacuum $\left(10^{6} \mathrm{mBar}\right.$ ) in the temperature range from RT to $1200 \mathrm{C}$ by a threepoint bending test (TPB). The heating rate was $10 \mathrm{C} / \mathrm{min}$ with a 10 min hold, the crosshead speed was $100 \mu \mathrm{m} / \mathrm{min}$, and the sample size was $2220 \mathrm{~mm}^{3}$. The fracture toughness was measured by a TPB test on a Single Edge Laser Notch Beam, with Femto -laser notching [9]. The stress intensity factor for mode I stress was then computed from the critical load and the beam section using the equation proposed by Guinea et al. [12].

The thermal transport properties were investigated using a Netzsch LFA 457 Microflash up to 1000 C. The LFA equipment allows a direct measurement of the thermal diffusivity, while the specific heat of the materials was determined by a differential method using a Molybdenum_SRM781 standard sample as a reference. The thermal conductivity was calculated using Equation (1):

$\begin{array}{llll}\lambda & \alpha & \rho & C_{p}\end{array}$

where $\rho$ is the density, $C_{p}$ is the specific heat and $\alpha$ is the thermal diffusivity of the material. The sample densities were measured using the Archimedes method and a high-resolution balance. Several measurements (up to five per material) were performed for each material.

\section{Results}

\subsection{Composition of the as-sintered samples}

Table 2 presents the expected (calculated from the starting powder composition) and measured contents of $\mathrm{W}_{2} \mathrm{C}$ in the samples prepared with various WC powder additions and sintered by FAST. The $\mathrm{W}_{2} \mathrm{C}$ content was determined by a Rietveld refinement analysis of the experimental XRD spectra using least-squares methods.

As presented in Table 2 and illustrated in Fig. 1, in the sample with the addition of $1 \mathrm{vol} \%$ of WC (W-1WC) no $\mathrm{W}_{2} \mathrm{C}$ was detected by XRD analysis. The same result was also obtained for the W-5WC where, according to the calculation, the expected $\mathrm{W}_{2} \mathrm{C}$ content was $8 \mathrm{wt} \%$. This was ascribed to the content below the detection limit of the laboratory XRD. At more massive additions of WC nanoparticles, as a source of carbon, the peaks in the XRD spectra of sintered samples confirmed the presence of the $\mathrm{W}_{2} \mathrm{C}$ secondary phase.

\subsection{Microstructure of the as-sintered samples}

Fig. 2a-e illustrate the characteristic fracture surfaces of the

Table 2

Content of $\mathrm{W}_{2} \mathrm{C}$ in $\mathrm{W}-\mathrm{W}_{2} \mathrm{C}$ composite samples, as calculated and analysed by XRD.

\begin{tabular}{|c|c|c|}
\hline Sample & $\begin{array}{l}\text { Calculated content of } \\
\mathrm{W}_{2} \mathrm{C} \text { (wt. \%) }\end{array}$ & $\begin{array}{l}\text { Content of } \mathrm{W}_{2} \mathrm{C} \text { as determined by Rietveld } \\
\text { refinement analysis (wt. \%) }\end{array}$ \\
\hline W & 0 & - \\
\hline W-1WC & 1.6 & $(*)$ \\
\hline W-5WC & 8 & $(*)$ \\
\hline W-10WC & 16 & $\begin{array}{ll}4 & 1\end{array}$ \\
\hline W-25WC & 41 & $30 \quad 2$ \\
\hline
\end{tabular}

(*) below the detection limit ( $<3 \mathrm{wt} \%)$. 


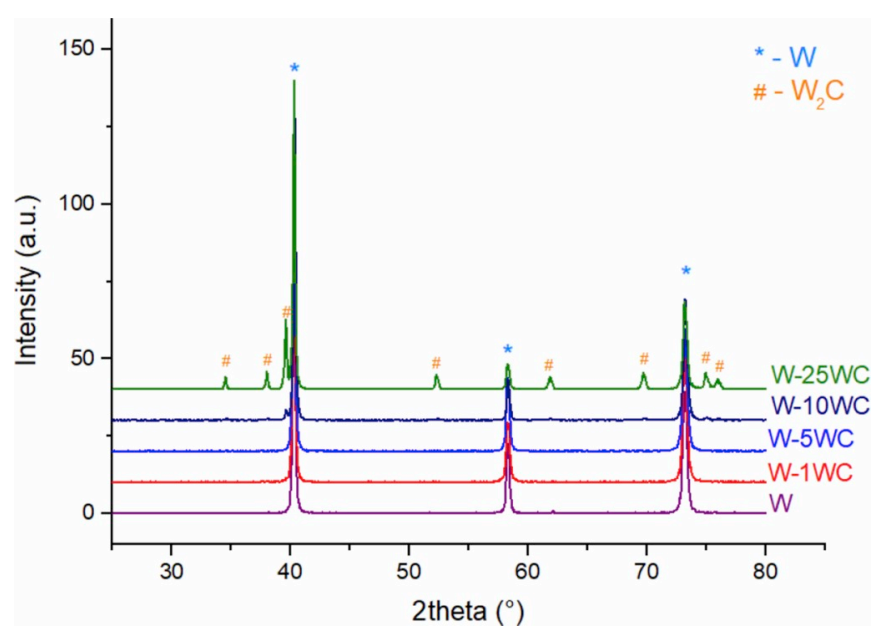

Fig. 1. XRD spectra of the as-sintered tungsten-based samples with increasing additions of WC in the starting composition. examined samples sintered by FAST for 5 min at 1900 C. For comparison, the microstructure of the pure tungsten sample sintered in the high-temperature vacuum furnace at $2200 \mathrm{C}$ for $6 \mathrm{~h}$ is presented in Fig. 2aa. Densification by FAST resulted in a finer microstructure and a much lower porosity when compared to the conventional sintering (Figs. 2a and 2aa, respectively). An important feature observed in the FAST-sintered tungsten is the presence of small, liquid-like, inclusions on the grain boundaries (inset in Fig. 2a), while in the conventionally sintered tungsten such inclusions were not observed. According to the results of XRD, TEM (with SAED) and EDS, presented in our previous study [13], these liquid-like inclusions in the FAST-densified tungsten are monoclinic tungsten dioxide $\mathrm{WO}_{2}$. This phase is presumably the main reason for the observed intergranular fracture; while in contrast, the transgranular fracture of the conventionally sintered W (Fig. 2aa) is caused by the pores within the grains. As the melting point of the $\mathrm{WO}_{2}$ $(1700 \mathrm{C})$ is below the sintering temperature by FAST (1900 C), we assume that the specific neck-shape of the observed $\mathrm{WO}_{2}$ inclusions results from its melting during sintering. Furthermore, this study also revealed that during prolonged heating at high temperature, the oxide evaporates, leaving behind voids (see Fig. 9b).

Similar to the FAST-sintered sample W, the sample W-1WC reveals
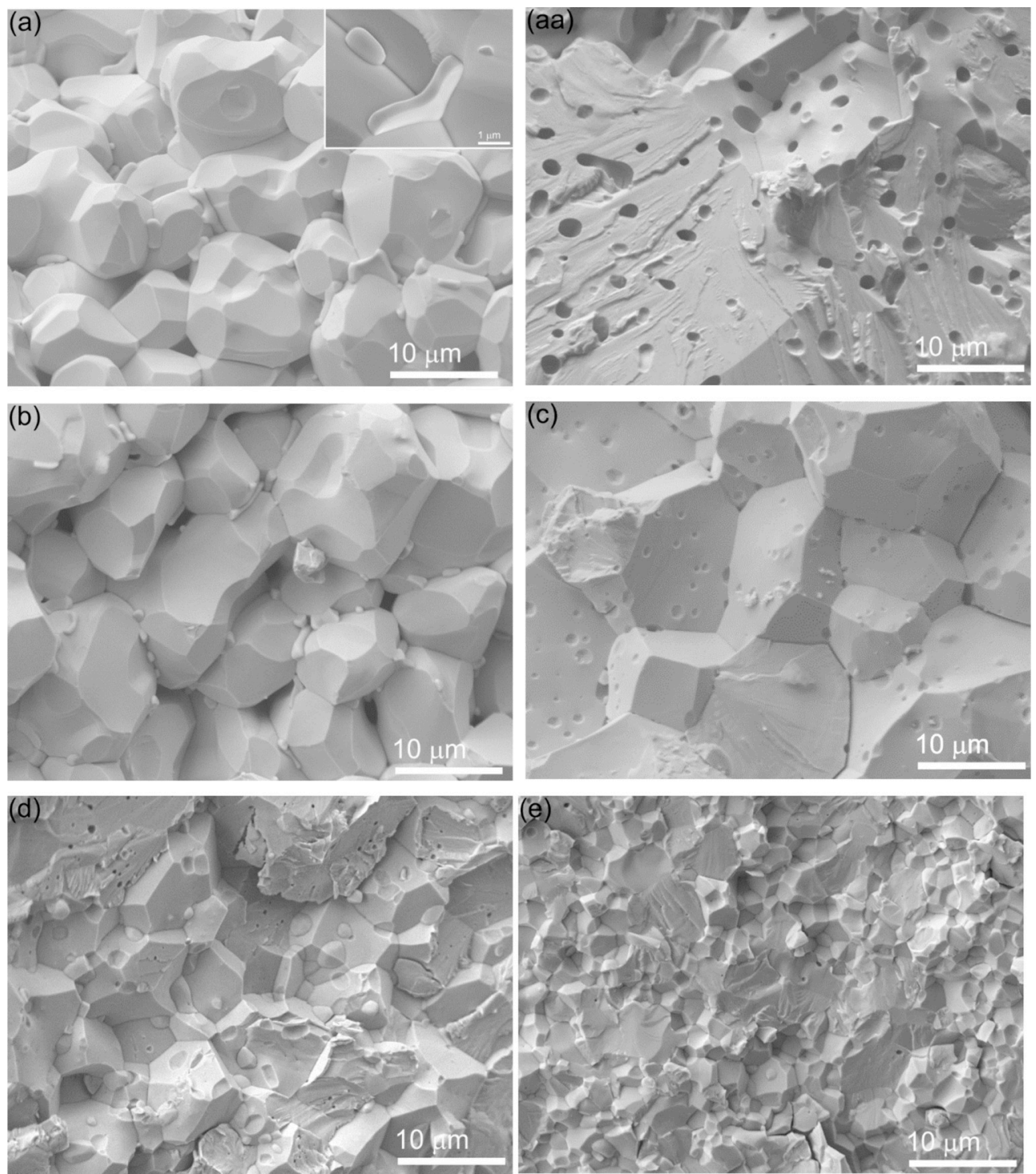

Fig. 2. Fracture surfaces of the samples W (a), W-1WC (b), W-5WC (c) W-10WC (d) and W-25WC (e), densified by FAST. A tungsten sample sintered in the hightemperature vacuum furnace is presented for comparison (aa). Inset in Fig. 2a: Secondary phase in the tungsten sample densified by FAST. All the samples were fractured at room temperature. 
the presence of the oxide inclusions at the W grain boundaries (Fig. 2b), while only a few such inclusions were observed in the microstructure of the sample with $5 \mathrm{vol} \% \mathrm{WC}$ addition (W-5WC, Fig. 2c). This suggests that the majority of the oxygen present in the initial $\mathrm{W}$ powder was consumed by carbon from the WC particles, leaving behind pure tungsten. The oxide inclusions were also not observed for the samples with 10 or 25 vol \% WC additions (Fig. $2 \mathrm{~d}$ and e, respectively). We assume that the carbon content was sufficiently high to consume all the oxygen present to form volatile products.

Moreover, the microstructures of the samples W-10WC (Fig. 2d) and W-25WC (Fig. 2e) revealed smaller grains than observed for the samples $\mathrm{W}, \mathrm{W}-1 \mathrm{WC}$ and $\mathrm{W}-5 \mathrm{WC}$. The average grain size, measured on polished surfaces of the samples was $10 \mu \mathrm{m}$ for $\mathrm{W}, 3.1 \mu \mathrm{m}$ for $\mathrm{W}-10 \mathrm{WC}$ and $2.0 \mu \mathrm{m}$ for $\mathrm{W}-25 \mathrm{WC}$. In the samples with a higher amount of added WC (W-10WC and W-25WC), we can observe small inclusions with different morphologies than observed for the $\mathrm{W}$ and $\mathrm{W}-1 \mathrm{WC}$. According to the results of the XRD analysis (see Table 2 and Fig. 1), these inclusions are hexagonal $\mathrm{W}_{2} \mathrm{C}$ grains formed from WC after losing a fraction of the carbon. It is clear that with the addition of WC in the starting mixture, the transgranular fracture mode is promoted.

Differentiation between the $\mathrm{W}$ and $\mathrm{W}_{2} \mathrm{C}$ using the conventional backscattered-electron (BSE-SEM) technique is, unfortunately, impossible, due to the strong channelling effect, produced by the random orientations of the $\mathrm{W}$ grains. The orientation contrast prevails over the small difference in Z-number between the $\mathrm{W}$ and the $\mathrm{W}_{2} \mathrm{C}$. Thus, for identification of the phases, we employed EBSD, which can distinguish between both phases in terms of their crystal structure instead of their chemical composition. The EBSD analysis confirmed the presence of small $\mathrm{W}_{2} \mathrm{C}$ inclusions on the $\mathrm{W}$ grain boundaries of the samples $\mathrm{W}-10 \mathrm{WC}$ (Fig. 3a) and W-25WC (Fig. 3b).

\subsection{Mechanical properties}

As illustrated in Fig. 4, the density of the FAST-sintered W-based materials increases with the increased WC addition and reaches more than $99 \%$ of the theoretical density with $25 \mathrm{vol} \%$ WC addition. Accordingly, the flexural strength also increases up to $10 \mathrm{vol} \%$ of added WC (sample W-10WC). This observation is consistent with the microstructures presented in Fig. 2, which suggested that the addition of $10 \mathrm{vol} \% \mathrm{WC}$ or more ensures the absence of the oxide phase and enables the formation of $\mathrm{W}_{2} \mathrm{C}$ particles at the tungsten grain boundaries.

To verify the effect of the $\mathrm{W}_{2} \mathrm{C}$ inclusions on the tungsten grain growth at high temperatures (such as possible boundary conditions in the DEMO device), we aged the sintered samples at $1600 \mathrm{C}$ for $24 \mathrm{~h}$. As illustrated by the light-grey bars in Fig. 4, during ageing, the flexural strength degrades for all the examined samples.

The samples W-10WC and W (as a reference) were further analysed for their flexural strength while heating in a vacuum. Fig. 5 shows that

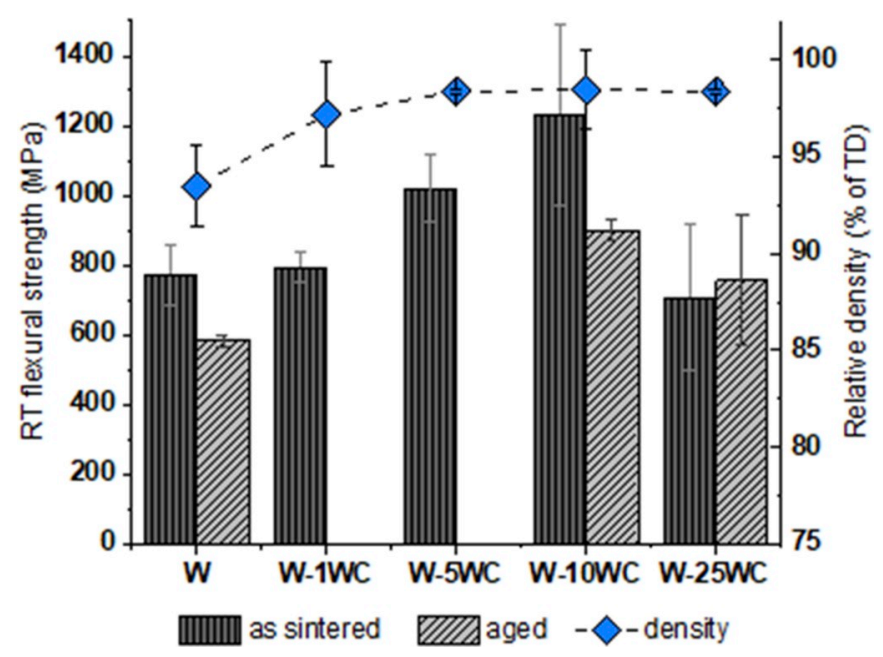

Fig. 4. Density and room-temperature flexural strength of the samples after sintering and after ageing for $24 \mathrm{~h}$ at $1600 \mathrm{C}$.

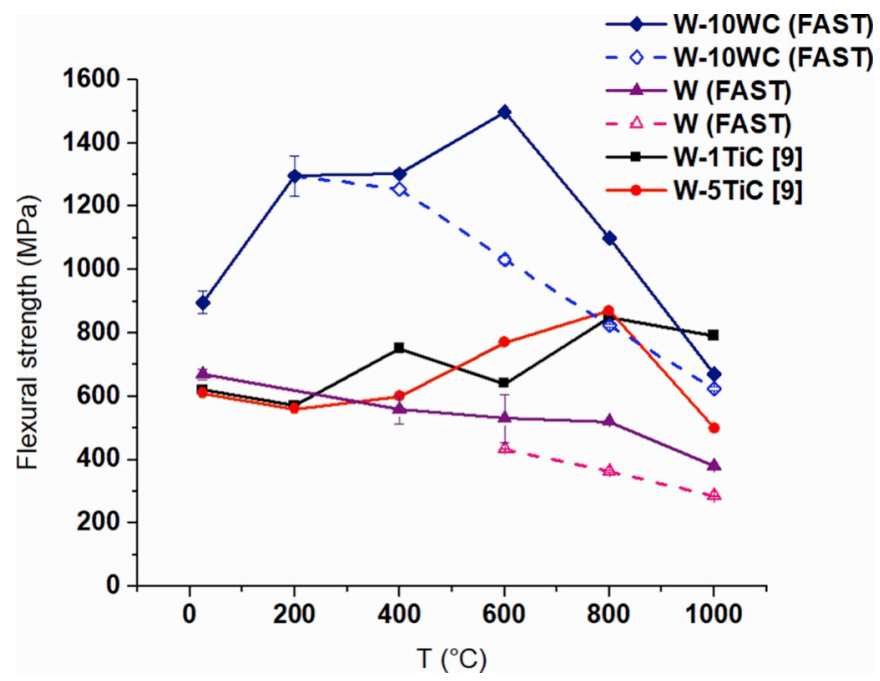

Fig. 5. Proof flexural strength of FAST-densified samples $\mathrm{W}$ and $\mathrm{W}-10 \mathrm{WC}$ as a function of temperature: ultimate flexural strength is plotted by solid lines and flexural yield strength (at $0.2 \%$ strain) by dashed lines. The bars for each point correspond to the standard error obtained for the mean value.
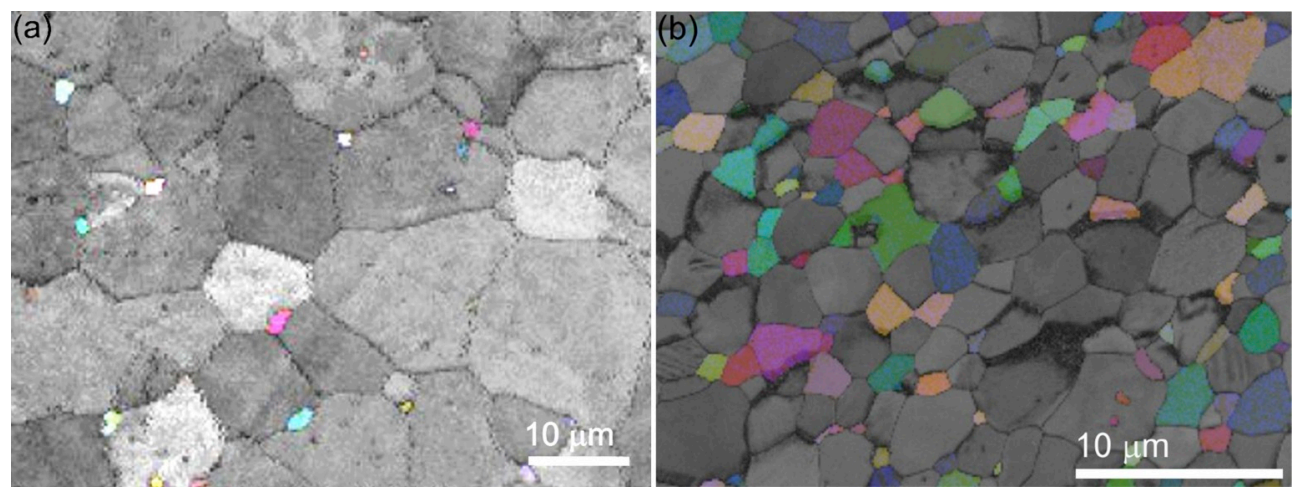

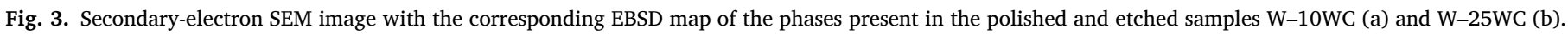

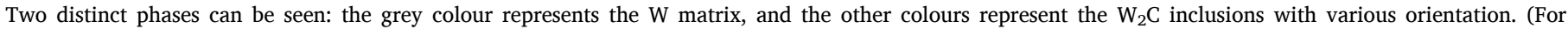
interpretation of the references to colour in this figure legend, the reader is referred to the Web version of this article.) 
the ultimate flexural strength (solid lines) for the W-10WC sample increases up to $600 \mathrm{C}(\sim 1500 \mathrm{MPa})$, at which point it starts to decrease. As the stress-strain curves in Fig. $6 \mathrm{a}$ and $\mathrm{b}$ imply that brittle fracture prevails only up to $400 \mathrm{C}$ for both $\mathrm{W}$ and $\mathrm{W}-10 \mathrm{WC}$, above this temperature the flexural yield strength (at $0.2 \%$ strain) is plotted with a dashed line. The values for W-10WC are much higher than those for the FAST-densified tungsten (W), for which the strength gradually decreases from $680 \mathrm{MPa}$ at room temperature to $300 \mathrm{MPa}$ at $1000 \mathrm{C}$. From the diagrams in Fig. 6a and b, it is also evident that for the W-10WC, not only the stress is significantly higher, but also the strain (deformation).

Fig. 7a presents the fracture toughness, $\mathrm{K}_{\mathrm{IQ}}$, for the $\mathrm{W}-\mathrm{W} 10 \mathrm{WC}$ as a function of temperature, while Fig. $7 \mathrm{~b}-\mathrm{d}$ illustrate the representative fracture surfaces after testing. Load-displacement curves were linear until fracture up to $800 \mathrm{C}$ when initial plastic behaviour was observed (represented as dashed lines in the graph). Up to this temperature, the stress intensity factor loses its validity and calculated values give only a lower bound of fracture toughness, i.e. apparent fracture toughness. The fracture toughness gradually increases with temperature, showing the highest value of toughness, $\sim 15 \mathrm{MPa} \mathrm{m}^{1 / 2}$, at $1000 \mathrm{C}$, due to the blunting of the crack tip. When the notch-tip radius (a few nanometres in size) starts to become rounded, the stress-intensity factor is locally reduced due to the geometrical patterns. As a result, the apparent fracture toughness, $\mathrm{K}_{\mathrm{IQ}}$, increases. The maximum macroscopic effect of this microstructural behaviour is reached at $1000 \mathrm{C}$, as seen in Fig. $7 \mathrm{a}$. Above this temperature, the degradation of the cohesive forces between grains, due to widespread plasticity (see Fig. 7d), results in a progressive degradation of the mechanical behaviour of the material. This behaviour is consistent with that observed in Fig. 5 for the flexural strength of the material.

\subsection{Thermal conductivity}

The thermal conductivity of up to five samples each from $\mathrm{W}$ and $\mathrm{W}-10 \mathrm{WC}$ was measured during heating up to $1000 \mathrm{C}$. The mean values obtained are presented in Fig. 8. The W-10WC exhibits a slightly lower thermal conductivity at moderate temperatures, compared to the W. Note that the FAST-densified tungsten has a slightly lower conductivity than the ITER-grade W [14] due to its lower density and the presence of $\mathrm{WO}_{2}$.

\subsection{Ageing at high temperature}

Fig. 9 a-d illustrate the effect of ageing at $1600 \mathrm{C}$ for $24 \mathrm{~h}$ on the microstructure of the W and W-10WC samples. A comparison of Fig. 9a and $\mathrm{b}$ reveals slightly larger $\mathrm{W}$ grains after ageing. We suppose that the $\mathrm{WO}_{2}$ inclusions act in a similar way as the carbide inclusions, i.e., they inhibit the tungsten grain growth. However, during prolonged heating, the inclusions evaporate due to the low melting point that enables the growth of the $\mathrm{W}$ grains. This assumption is supported by the microstructure in Fig. 9b, which reveals the absence of oxide inclusions. In contrast, the $\mathrm{W}_{2} \mathrm{C}$ inclusions at the tungsten grain boundaries in the sample W-10WC are stable under these conditions (1600 C, 24 h), which results in a nearly unchanged microstructure after ageing (Fig. 9c and d).

\section{Discussion}

The Field-Assisted Sintering Technology (FAST) has opened up new possibilities for the sintering of refractory materials, including tungsten. It was proven to be an advantageous technique for the rapid densification of pure and doped tungsten [15]. However, as the tungsten powder usually contains an oxide layer on the surface [16], the presence of oxides appears to be more problematic than in conventional sintering. In conventional sintering, a hydrogen atmosphere is used as an efficient reducing agent, but this is not applicable in FAST as the densification is driven by pulsed electric current. Due to the extremely high heating rate, it seems that there is not enough time for the formation and evaporation of gaseous products. As an alternative, carbon could be added, but this is related to the possible presence of unwanted residual free carbon [11]. Thus, the addition of a "sacrificial" phase such as WC, capable of "donating" the required amount of carbon for the reaction with oxygen, while leaving only tungsten behind, appears to be a favourable option. As presented in this work, at least $5 \mathrm{vol} \%$ of WC addition is needed for the elimination of the $\mathrm{WO}_{2}$ from the tungsten matrix that beneficially affects the density and flexural strength of the tungsten (see Fig. 4). It has to be taken into account, however, that the decarburisation of WC during sintering depends directly on the content and nature of oxygen in the starting powders [16].

Moreover, as presented in this work, the more substantial addition of submicron WC powder to the tungsten beneficially affects the microstructure and mechanical properties of the material. XRD and EBSD analyses confirmed that $\mathrm{W}_{2} \mathrm{C}$ is formed during the FAST densification of $\mathrm{W}$-WC mixtures. This observation is in agreement with the $\mathrm{W}-\mathrm{C}$ phase diagram, showing $\mathrm{WC}$ and $\mathrm{W}_{2} \mathrm{C}$ as the only stable phases in the temperature range of the sintering [17]. The $\mathrm{W}_{2} \mathrm{C}$ particles formed by decarburisation of the WC nanoparticles within the $\mathrm{W}$ matrix pin the grain boundaries to prevent tungsten grain growth at high temperatures. A similar effect was also observed for pores, $\mathrm{Y}_{2} \mathrm{O}_{3}, \mathrm{TiC}$ and $\mathrm{TaC}$ inclusions $[7,18]$. However, oxide inclusions may degrade the thermal conductivity, while $\mathrm{TiC}$ and $\mathrm{TaC}$ form mixed carbides $(\mathrm{W}, \mathrm{Ti}) \mathrm{C}_{1-\mathrm{x}}$ and $\mathrm{(W}$, Ta) $)_{1-x}$ over a wide range of compositions, which might lead to the growth of the carbide particles after prolonged heating.

The $\mathrm{W}-\mathrm{W}_{2} \mathrm{C}$ composites lead to a significantly improved density and mechanical properties at room as well as at high temperatures (Figs. 4 and 5). A significant improvement is already achieved by the addition of $5 \% \mathrm{WC}$, which results in dense tungsten without $\mathrm{WO}_{2}$ or $\mathrm{W}_{2} \mathrm{C}$ inclusions (Fig. 2d). In comparison with this sample, favourable characteristics were observed in particular for the sample W-10WC containing $4 \mathrm{wt} \%$
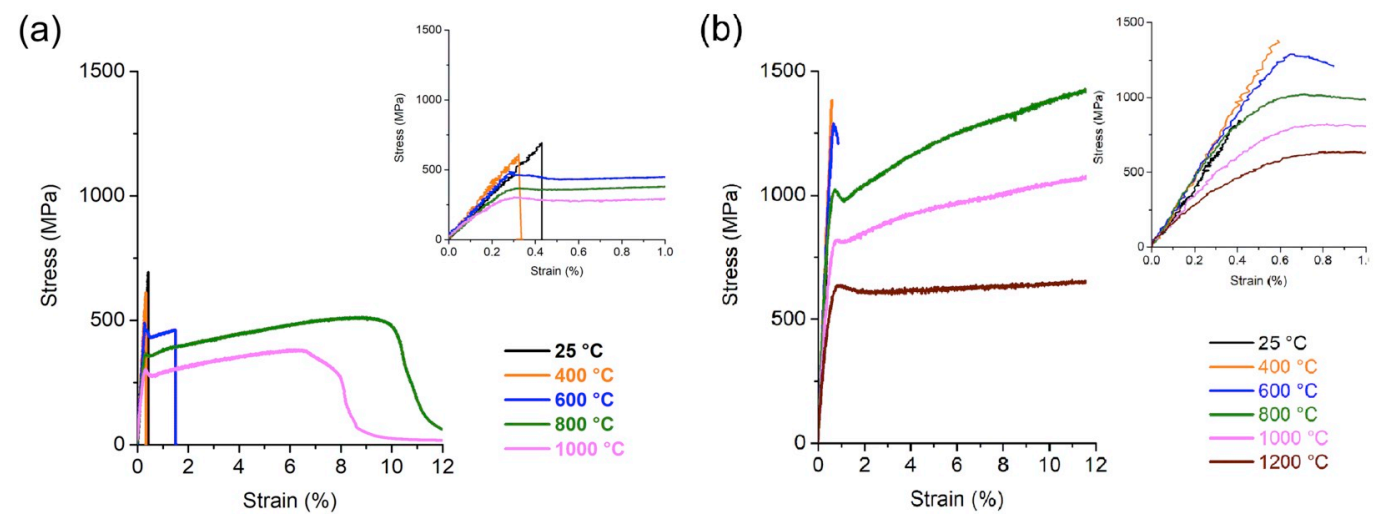

Fig. 6. Flexural stress-strain curves for FAST-densified W (a) and W-10WC (b). 
(a)

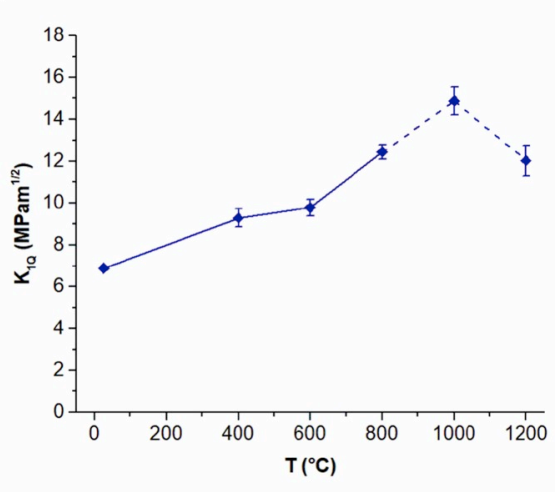

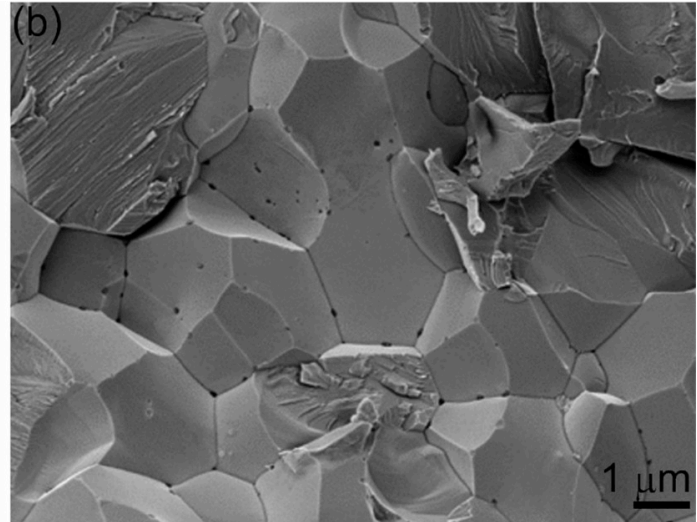

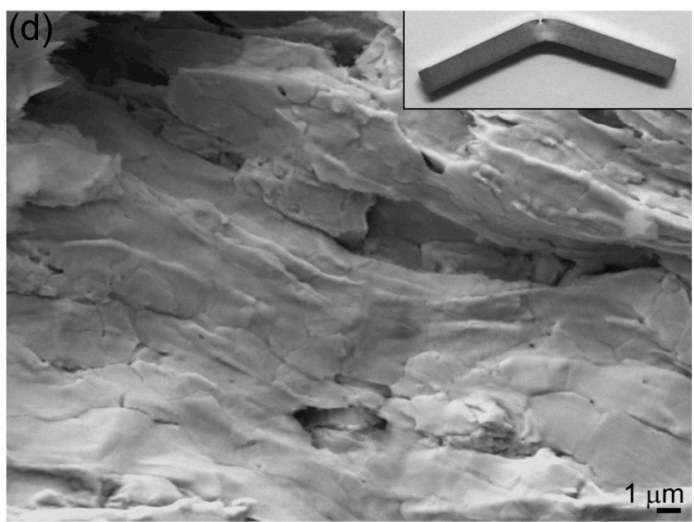

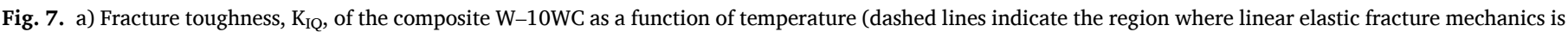

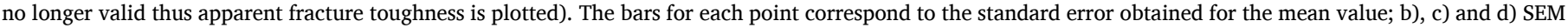
micrographs of fracture surfaces after testing at RT, $600 \mathrm{C}$, and $1200 \mathrm{C}$, respectively.

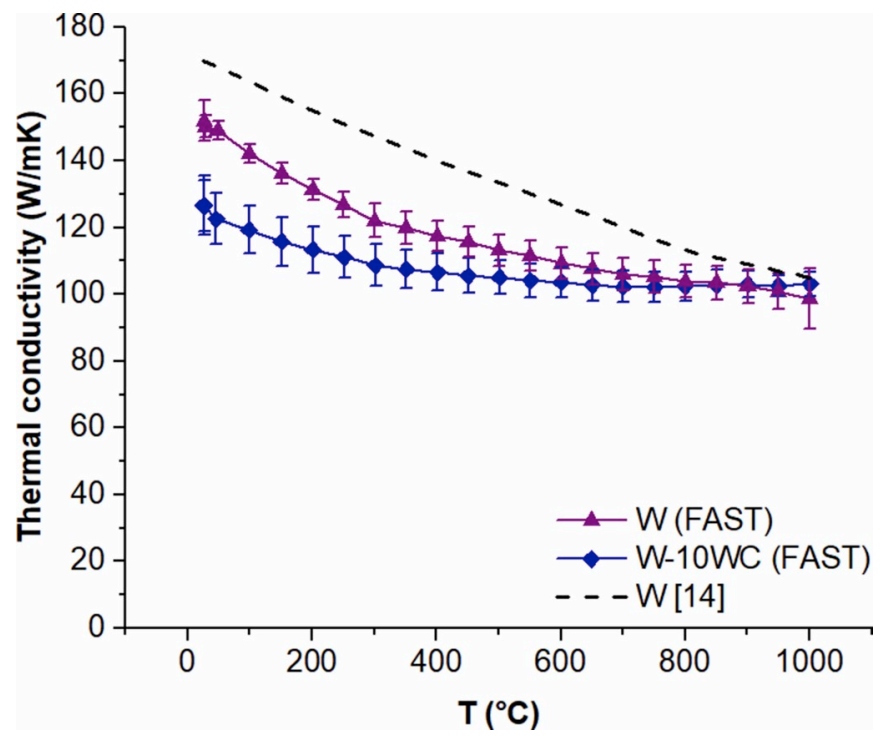

Fig. 8. Mean thermal conductivity curves for the FAST-densified $W$ and W-10WC samples in comparison with pure W presented in Ref. [14].

$\mathrm{W}_{2} \mathrm{C}$ after sintering. The addition of $\mathrm{WC}$ to the $\mathrm{W}$-matrix also promotes a transgranular fracture mode (see Fig. 9), which suggests cleaner and stronger grain boundaries. We assume that this is mainly a consequence of the absence of an oxide phase, but, despite being considered as a brittle phase, the $\mathrm{W}_{2} \mathrm{C}$ beneficially affects the strength.

As presented in Figs. 5 and 6, the flexural strength of the W-10WC is much higher in comparison with the tungsten over a wide range of temperatures up to $1200 \mathrm{C}$ and more extensive plastic deformation is enabled. The obtained flexural strength for $\mathrm{W}-10 \mathrm{WC}$ is also significantly higher in comparison with the values for W-1TiC and W-5TiC, measured by the same technique and reported by Tejado [9]. Furthermore, the composites $\mathrm{W}-1 \mathrm{TiC}$ and $\mathrm{W}-5 \mathrm{TiC}$ exhibit the onset of plastic deformation at a higher temperature, i.e., at $1200 \mathrm{C}$ and $1000 \mathrm{C}$, respectively [9], while in the case of $\mathrm{W}-10 \mathrm{WC}$ this was already observed at $600 \mathrm{C}$ (see Fig. 6). Overall, when the flexural strength for the W-10WC is compared with the literature data for the temperature-related strength of tungsten reinforced with $\mathrm{TiC}$, TaC or $\mathrm{Y}_{2} \mathrm{O}_{3}$ particles $[19,20]$, the $\mathrm{W}_{2} \mathrm{C}$ inclusions seem to have the most beneficial effect.

The observed relatively low flexural strength of the FAST-densified W could be ascribed to the high porosity and the presence of oxide inclusions (see Fig. 2a). For comparison, most of the values for pure polycrystalline tungsten reported within the last decade suggest a roomtemperature strength up to $600 \mathrm{MPa}$ and its decrease with temperature. Much higher values were only reported for the rolled tungsten produced by Plansee, reaching $1500 \mathrm{MPa}$ at $800 \mathrm{C}$ [9].

The fracture toughness of the W-10WC is slightly lower in comparison with the W-1TiC and W-5TiC reported by Tejado [9] and similar to the Charpy toughness reported by Reiser et al. [21]. While at $400 \mathrm{C}$, the brittle fracture can be observed, at $600 \mathrm{C}$ plastic deformation is evident (Fig. 6b). This temperature is slightly higher than reported for the rolled $\mathrm{W}$ [2]. On the other hand, the composite material shows certain advantages over tungsten: in particular, more stable microstructure and mechanical properties at high temperature, which is due to the inhibition of W-grain growth. While at temperatures below $600 \mathrm{C}$ (brittle region) strong cohesion between the $\mathrm{W}$ grains was observed (Fig. 7b), intergranular cracks appeared in the region from $600 \mathrm{C}$ to $1000 \mathrm{C}$ (Fig. 7c). The peak value of the apparent fracture toughness 

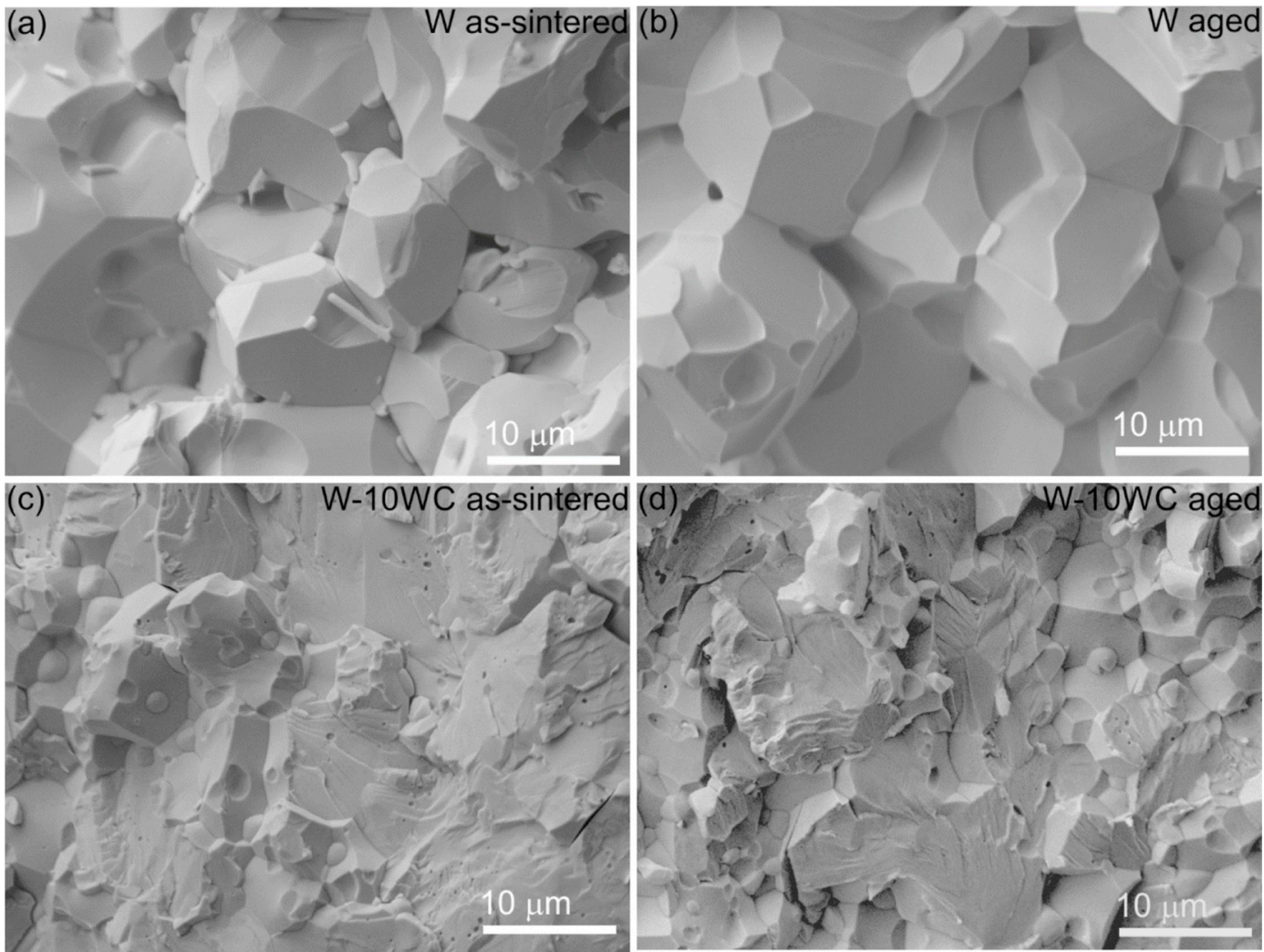

Fig. 9. Fracture surfaces (SEM) of the FAST-densified samples W and W-10WC before (a and c, respectively) and after ageing (b and d, respectively) at $1600 \mathrm{C}$ for $24 \mathrm{~h}$.

$\left(\sim 14.6 \mathrm{MPa} \mathrm{m}^{1 / 2}\right)$ was observed at $1000 \mathrm{C}$, where gross plastic deformation was observed next to the crack opening (Fig. $7 \mathrm{~d}$ ).

While there are many literature data on the flexural strength and ductility of pure and particle-reinforced tungsten as a function of temperature, the data on the effect of high-temperature ageing on mechanical properties is very scarce. For example, Reiser et al. [21] analysed the toughness of $\mathrm{W}$ plate over a wide range of temperatures after prolonged ageing and found that the Charpy toughness abruptly decreases after $1000 \mathrm{~h}$. A massive degradation of mechanical properties at $600 \mathrm{C}$ was also observed for mechanically alloyed and subsequently, hot isostatically pressed $\mathrm{W}$ with $\mathrm{Y}_{2} \mathrm{O}_{3}$ [22]. On the other hand, the results of this study reveal that ageing at $1600 \mathrm{C}$ for $24 \mathrm{~h}$ negligibly affected the microstructure of $\mathrm{W}-10 \mathrm{WC}$ and a decrease in the flexural strength from $1330 \mathrm{MPa}$ to $900 \mathrm{MPa}$.

\section{Conclusions}

Here we report on the development of new composite material for use in the DEMO divertor. At this stage, the microstructure, mechanical properties, thermal stability and thermal conductivity were analysed with the aim to select the most favourable composition.

The particle reinforcement of tungsten was achieved by incorporating $\mathrm{WC}$ nanoparticles as a precursor to the $\mathrm{W}_{2} \mathrm{C}$ inclusions. The $\mathrm{W}_{2} \mathrm{C}$ particles are formed at the tungsten grain boundaries during densification by carbon diffusion from the WC particles. After densification by FAST at $1900 \mathrm{C}, 5 \mathrm{~min}$, two phases are detected in the sintered composite: cubic $\mathrm{W}$ and hexagonal $\mathrm{W}_{2} \mathrm{C}$, which implies the complete transformation of the WC. No oxide was detected in the $\mathrm{W}-\mathrm{W}_{2} \mathrm{C}$ composites, in contrast to the FAST-densified pure tungsten, where the oxide phase was found on the $\mathrm{W}$ grain boundaries.

The addition of at least $5 \mathrm{vol} \%$ of the submicron WC successfully prevented the oxidation of $\mathrm{W}$, while larger amounts contributed to the beneficial formation of the desired carbide particle $\mathrm{W}_{2} \mathrm{C}$, which inhibits tungsten grain growth during ageing at high temperatures. The composite with the addition of approximately $10 \mathrm{vol} \%$ WC inclusions (sample W-10WC) reflects the highest flexural strength at RT $(>1200 \mathrm{MPa})$ as well as at elevated temperatures, with the onset of plastic deformation at $600 \mathrm{C}$. Moreover, the high-temperature thermal conductivity is relatively high and remains above $100 \mathrm{Wm} / \mathrm{K}$ up to $1000 \mathrm{C}$. Thus, the results suggest improved properties of this composite in comparison with state-of-the-art materials, and therefore the material will be subject to high-heat-flux testing.

\section{Data-availability statement}

The data that support the findings of this study are available from the corresponding author upon request.

\section{Acknowledgement}

This work has been carried out within the framework of the EUROfusion Consortium and has received funding from the Euratom research and training programme 2014-2018 and 2019-2020 under grant agreement No 633053. The views and opinions expressed herein do not necessarily reflect those of the European Commission. Parts of the work have been performed within the PhD studies of Mrs Andreja Sestan Zavasnik and Mr Matej Kocen; both supported within the Eurofusion education \& training scheme. This project has received funding from the Slovenian Research Agency (Contracts No. 1000-17-0106, J2-8165, P20087-2 and P2-0405-5). The authors also acknowledge the support of the Ministerio de Economía y Competitividad of Spain (research project MAT2015-70780-C4-4-P) and the Comunidad de Madrid (research project S2018/NMT-4411 ADITIMAT-CM) who have co-funded this research. 


\section{Appendix A. Supplementary data}

Supplementary data to this article can be found online at https://doi. org/10.1016/j.msea.2019.138666.

\section{References}

[1] M. Rieth, et al., Review on the EFDA programme on tungsten materials technology and science, J. Nucl. Mater. 417 (1-3) (2011) 463-467.

[2] M. Rieth, et al., Recent progress in research on tungsten materials for nuclear fusion applications in Europe, J. Nucl. Mater. 432 (1-3) (2013) 482-500.

[3] A.F. Rowcliffe, et al., Materials-engineering challenges for the fusion core and lifetime components of the fusion nuclear science facility, Nucl. Mater. Energy 16 (2018) 82-87.

[4] P. Gumbsch, et al., Controlling factors for the brittle-to-ductile transition in tungsten single crystals, Science 282 (5392) (1998) 1293-1295.

[5] P. Norajitra, Divertor Development For A Future Fusion Power Plant, KIT scientific publishing, 2014, pp. 33-43, 150 pages.

[6] Y. Kim, et al., Fabrication of high temperature oxides dispersion strengthened tungsten composites by spark plasma sintering process, Int. J. Refract. Metals Hard Mater. 27 (5) (2009) 842-846.

[7] Y. Kitsunai, et al., Microstructure and impact properties of ultra-fine grained tungsten alloys dispersed with TiC, J. Nucl. Mater. 271 (1999) 423-428.

[8] S. Lang, et al., Microstructure, basic thermal-mechanical and Charpy impact properties of W-0.1 wt.\% TiC alloy via chemical method, J. Alloy. Comp. 660 (2016) 184-192.

[9] E.M.G. Tejado, Performance of Structural Materials for the DEMO Divertor, $\mathrm{PhD}$ Thesis, 2017 (Universidad Politecnica de Madrid).

[10] S. Antusch, et al., Mechanical and microstructural investigations of tungsten and doped tungsten materials produced via powder injection molding, Nucl. Mater. Energy (2015) 22-31, 3-4.
[11] P. Jenus, et al., W2C-reinforced tungsten prepared using different precursors, Ceram. Int. 45 (6) (2019) 7995-7999.

[12] G.V. Guinea, et al., Stress intensity factor, compliance and CMOD for a general three-point-bend beam, Int. J. Fract. 89 (2) (1998) 103-116.

[13] A. Sestan, et al., The role of tungsten phases formation during tungsten metal powder consolidation by FAST: implications for high-temperature applications, Mater. Char. 138 (2018) 308-314.

[14] A. Von Muller, et al., Melt infiltrated tungsten-copper composites as advanced heat sink materials for plasma facing components of future nuclear fusion devices, Fusion Eng. Des. 124 (2017) 455-459.

[15] E. Autissier, et al., Spark plasma sintering of pure and doped tungsten as plasma facing material, Phys. Scr. (2014), 014034.

[16] A.S. Kurlov, Effects of vacuum annealing on the particle size and phase composition of nanocrystalline tungsten carbide powders, Russ. J. Phys. Chem. 87 (4) (2013) 654-661.

[17] A. Kurlov, A. Gusev, Tungsten carbides and WC phase diagram, Inorg. Mater. 42 (2) (2006) 121-127.

[18] C.H. Worner, P.M. Hazzledine, Grain-growth stagnation by inclusions or pores, Jom-J. Miner. Metals Mater. Soc. 44 (9) (1992) 16-20.

[19] G.M. Song, Y. Zhou, Y.J. Wang, The microstructure and elevated temperature strength of tungsten-titanium carbide composite, J. Mater. Sci. 37 (16) (2002) 3541-3548.

[20] F. Lukac, et al., Properties of mechanically alloyed W-Ti materials with dual phase particle dispersion, Metals (1) (2017) 7.

[21] J. Reiser, et al., Ductilisation of tungsten (W): on the increase of strength AND room-temperature tensile ductility through cold-rolling, Int. J. Refract. Metals Hard Mater. 64 (2017) 261-278.

[22] T. Palacios, et al., Mechanical characterisation of tungsten-1 wt.\% yttrium oxide as a function of temperature and atmosphere, J. Nucl. Mater. 454 (1-3) (2014) $455-461$. 